\title{
Novel Approach: Tungsten Oxide Nanoparticle as a Catalyst for Malonic Acid Ester Synthesis via Ozonolysis
}

\author{
Bilal A. Wasmi, ${ }^{1}$ Ahmed A. Al-Amiery, ${ }^{1,2}$ \\ Abdul Amir H. Kadhum, ${ }^{1}$ and Abu Bakar Mohamad ${ }^{1}$ \\ ${ }^{1}$ Department of Chemical and Process Engineering, Faculty of Engineering and Built Environment, Universiti Kebangsaan Malaysia, \\ Bangi, 43600 Selangor, Malaysia \\ ${ }^{2}$ Environmental Research Center, University of Technology, Baghdad 10066, Iraq
}

Correspondence should be addressed to Ahmed A. Al-Amiery; dr.ahmed1975@gmail.com

Received 23 June 2014; Revised 30 July 2014; Accepted 2 August 2014; Published 24 August 2014

Academic Editor: Yogendra Mishra

Copyright (C) 2014 Bilal A. Wasmi et al. This is an open access article distributed under the Creative Commons Attribution License, which permits unrestricted use, distribution, and reproduction in any medium, provided the original work is properly cited.

\begin{abstract}
Malonic acid ester was synthesized via the one-step ozonolysis of palm olein. Malonic acid ester was spectroscopically characterized using gas chromatography mass spectroscopy (GC-MS). Tungsten oxide nanoparticles were used as the catalyst, which was characterized via X-ray powder diffraction (XRD) and field emission scanning electron microscopy (FE-SEM). Tungsten oxide provided several advantages as a catalyst for the esterification malonic acid such as simple operation for a precise ozonation method, an excellent yield of approximately $10 \%$, short reaction times of $2 \mathrm{~h}$, and reusability due to its recyclability.
\end{abstract}

\section{Introduction}

Nanotechnology presents new opportunities to create better materials and products. Nanomaterials find wide applications in catalysis, energy production, medicine, environmental remediation, automotive industry, and other sectors of our society. Nanomaterial-containing products are already available globally and include automotive parts, defense application, drug delivery devices, coatings, computers, clothing, cosmetics, sports equipment, and medical devices [1-7]. Tungsten trioxide nanoparticles have received significant attention for their unique properties. Tungsten exhibits many oxidation states, that is, 2, 3, 4, 5 and 6 , and tungsten compound can exist in many forms. For instance, typical tungsten oxides include tungsten (VI) oxide $\left(\mathrm{WO}_{3}\right.$, lemon yellow appearance) and tungsten (IV) oxide $\left(\mathrm{WO}_{2}\right.$, brown and blue appearance) [8]. Several applications such as electrochromic [9], photochromic [10], and gas sensing [11-13] have been developed for such oxides, and tungsten oxide is one of the very few highly visible-light-active single-phase oxide photocatalysts [14-17]. $\mathrm{WO}_{3}$ nanoparticles or nanocrystallites have been synthesized using various techniques such as pyrolysis [11, 12], thermal decomposition [18], and wet chemical processes such as sol-gel [19], colloidal processes [20], and ion-exchange methods [21, 22].

Because of their band gap situated within the solar spectrum range, tungsten oxides are one of the solar energy transforming materials leading to applications of catalytic activity and photoconductivity [23]. Of special interest is the preparation of nanostructured tungsten oxide since nanometric structures exhibit novel properties due to large number of surface atoms and or three-dimensional confinement of electrons. Various methods including pyrolysis, thermal decomposition, wet chemical process such as sol gel, and colloidal and ion exchange method have been used to prepare $\mathrm{WO}_{3}$ nanostructures [24-27]. Tree like structure has been observed by heating a tungsten foil, partly covered by $\mathrm{SiO}_{2}$ in $\mathrm{Ar}$ atmosphere at $1600^{\circ} \mathrm{C}$, whereas $\mathrm{WO}_{2}$ nanowires have been reported by heating tungsten wire under $\mathrm{N}_{2}$ at the same temperature $[28,29]$. Tungsten hot filaments have previously been used to prepare tungsten oxide nanostructures but studies on how to control the synthesis conditions to prepare different nanostructures are not yet clear [30]. 
A proper understanding of the growth mechanism of nanostructure of $\mathrm{WO}_{3}$ is essential for designing a wellcontrolled synthesis method. In the past, a variety of strategies have been developed to achieve growth of tungsten oxide. Generally, there are three distinct growths in tungsten oxides, though the mechanisms involved in each can often overlap. It refers to those materials that have the natural tendency towards growth due to their intrinsic highly anisotropic crystallographic structure. Such anisotropic growth most commonly exists in vapour deposition synthesis [31-33]. The second growth mechanism was self-assembly, and it refers to the fact that the nanostructures organise themselves to form morphology based on chemical and energetic influences [34]. The third mechanism named template directed growth represents a straightforward route to nanostructures. It involves the use of a scaffold within which a different material is generated in situ and shaped into a nanostructure with its morphology complementary to that of the template [35].

Ozonolysis is of great interest to synthetic organic chemistry because it is one of the most efficient tools for oxidatively cleaving carbon-carbon double bonds [36]. Ozonolysis is generally used to prepare biologically active molecules. Therefore, the reactions between ozone and organic compounds [37] continue to be a subject of significant interest from mechanistic, synthetic, and environmental perspectives [38]. The importance of $\mathrm{O}_{3}$ reactions with alkenes in the troposphere and solution has led to many experimental and theoretical studies of their kinetics and mechanism [39].

The present work addresses tungsten oxide nanoparticle syntheses for use as a catalyst in the novel one-step synthesis of malonic acid ester. Malonic acid ester is directly synthesized and esterified via the ozonolysis of palm olein (palm oil fraction), which comprises 10\% linoleic acid as an unsaturated fatty acid. The main advantages of using tungsten oxide nanoparticles as the catalyst for this esterification are to shorten the reaction time. Using tungsten oxide nanoparticles also has minor advantages such as simple synthetic operation, excellent yields, and recyclability. The structure and size of the tungsten oxide nanoparticles were investigated via field emission scanning electron microscopy (FE-SEM) and Xray powder diffraction (XRD). The malonic acid ester was spectroscopically characterized via gas chromatography mass spectroscopy (GC-MS).

\section{Experimental Section}

2.1. Materials. The palm olein (fractionated palm oil) starting material was purchased from the Lam Soon Company. All chemicals were purchased from Sigma Aldrich. The compound purities were checked via thin-layer chromatography (TLC) on silica gel G plates using benzene-ethyl acetatemethanol $40: 30: 30(\mathrm{v} / \mathrm{v})$ or toluene-acetone $75: 25(\mathrm{v} / \mathrm{v})$ as the mobile phase; the spots were visualized under UV light at 254 and $365 \mathrm{~nm}$. The GC/MS analyses were performed using an Agilent 7890A gas chromatograph (GC) directly coupled to an Agilent 5975C inert MSD mass spectrometer (MS) system with a triple-axis detector. The column was a
DB-5 MS UI model with a 5\% phenyl methyl polysiloxane stationary phase.

2.2. Methods. Oxygen gas was fed into the electric ozone generator at a flow rate of $1 \mathrm{~L} / \mathrm{min}$ and pressure of $0.03 \mathrm{MPa}$ to generate the ozone gas that was directed into the reactor containing palm olein as fine bubbles. The reaction temperature was maintained at $150^{\circ} \mathrm{C}$ for $2 \mathrm{~h}$ with vigorous stirring. The unreacted ozone was decomposed before mixing with the atmosphere. The ozonation products were further oxidized for $30 \mathrm{~min}$ using hydrogen peroxide using a 10:90 (w/w) ratio of hydrogen peroxide to ozonolysis products as shown in Scheme 1. The products were subsequently subjected to a liquid-liquid extraction using hexane.

Tungsten trioxide NPs are commercially available and can be synthesized via an acid precipitation according to [40]. This precipitation technique was used to synthesize the $\mathrm{WO}_{3}$ nanoparticles from aqueous ammonium tungstate para pentahydrate $\left(\left(\mathrm{NH}_{4}\right)_{10} \mathrm{~W}_{12} \mathrm{O}_{41} \cdot 5 \mathrm{H}_{2} \mathrm{O}\right)$ and nitric acid $\left(\mathrm{HNO}_{3}\right)$ solutions. A predetermined amount of the tungstate salt was dissolved in deionized water, and the resulting solution was heated to $80^{\circ} \mathrm{C}$. After vigorous stirring, a warm, concentrated nitric acid was added dropwise. The amount of tungstate salt and nitric acid used was fixed so that the final concentration for both reactants ranged from 5.3 to $16.0 \mathrm{mM}$. The mixture was kept at $80^{\circ} \mathrm{C}$ for $60 \mathrm{~min}$ with continuous stirring before the precipitates were allowed to settle for 1 day at room temperature. The precipitate was washed by the addition of a large amount of deionized water, stirring for approximately $10 \mathrm{~min}$, and allowing the precipitates to settle overnight before decanting the liquid. This washing procedure was performed twice. Finally, the precipitates were separated via ultrafiltration using a polymer membrane (pore size $=0.47 \mathrm{~mm}$ ). After drying overnight at $100^{\circ} \mathrm{C}$, the precipitates were calcined in air at temperatures ranging from 150 to $800 \mathrm{C}$ for $2 \mathrm{~h}$. The size, content, and shape of the tungsten oxide were confirmed using X-ray diffraction (XRD) and field emission scanning electron microscopy (FESEM). The product was purified, separated, and characterized via gas chromatography-mass spectrometry (GC-MS).

\section{Results and Discussion}

3.1. Chemical Analysis of Malonic Acid Ester and Nanoparticles. Malonic acid ester was synthesized via high pressure ozonolysis using tungsten oxide nanoparticles as the catalyst in ethanol. The synthetic reaction sequence for the malonic acid ester is outlined in Scheme 2. The starting material was palm oil, which is commercially available. Palm oil is composed of fatty acids, namely, myristic (saturated C14), palmitic (saturated C16), stearic (saturated C18), oleic (monounsaturated C18), and linoleic (polyunsaturated C18) acids. The two unsaturated long chain carboxylic acids in palm oil are oxidized via high pressure ozonolysis. The oxidation of linoleic acid yields azelaic acid, malonic acid, and hexanoic acid. The mass spectrum provides good evidence for the malonic acid formation. The ozonolysis mechanism suggested by Criegee cleaves alkene double bonds via their 


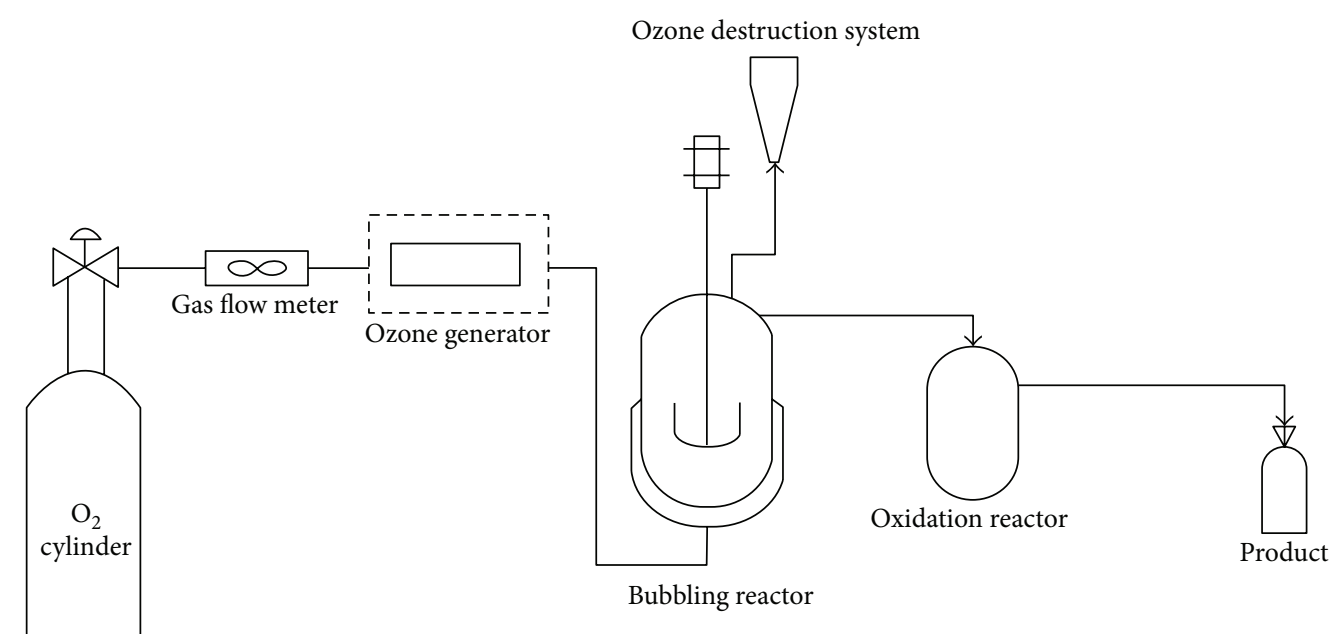

SCHEME 1: Systematic diagram of the ozonolysis process.<smiles></smiles><smiles>CCCCCC12OOOC1CC1COOC1OO2</smiles><smiles>CCCC</smiles><smiles></smiles><smiles>CCCCCC1OOC(CC2OOC(CCCCCCCC(=O)O)O2)O1</smiles>
$\mathrm{H}_{2} \mathrm{O}_{2} / \mathrm{WO}_{3}$<smiles>CCCCCC(=O)O</smiles><smiles>O=C(O)CCCCCCCC(=O)O</smiles>

SCHEME 2: Synthesis of malonic acid. 


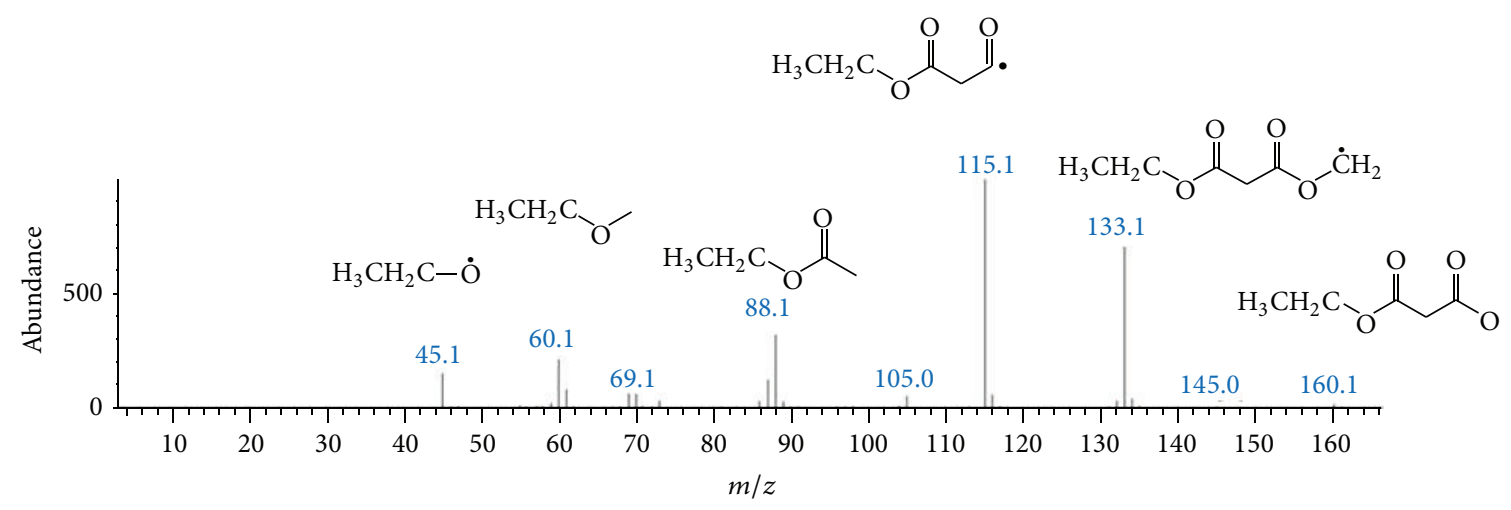

Figure 1: Mass spectrum fragmentations of malonic acid ethyl ester.

reaction with ozone [41]. The highly exothermic 1,3-dipolar cycloaddition of ozone to linoleic acid forms the Criegee intermediate called trioxolane, which decomposes into a carbonyl oxide and carbonyl compound (Scheme 2). The oxide and carbonyl react again via a 1,3-dipolar cycloaddition to produce a relatively stable ozonide intermediate.

3.1.1. Mass Spectroscopy of Malonic Acid Ethyl Ester. The spectrum of the investigated malonic acid ethyl ester exhibited molecular ion peaks (with $\mathrm{m} / \mathrm{z}$ values corresponding to the molecular weight) for malonic acid ethyl ester. The abundant malonic acid ethyl ester fragment (base peak) was at $(\mathrm{m} / z$ $160)$. According to the fragmentation peak at $(m / z 145)$, the fragments formed from the breaking of the bond between the carbon-carbon atoms in the ethyl group. The fragmentation peak at $(m / z 115)$ was from the bond between the oxygen and carbon in the methylene group cleavaging. The fragmentation peaks at $(m / z 115, m / z 88$, and $m / z 60)$ were due to the loss of oxygen and carbon mono oxide, respectively. The fragmentation peak at $(m / z 60)$ was due to the cleavage of the hydroxyl group, and finally, the fragmentation peak 7 at $(\mathrm{m} / z$ 45) was due to the cleavage of the methyl group, (Figure 1).

3.1.2. FESEM Morphologies of the Synthesized Nanoparticles. Field Emission Scanning Electron Microscopy (FE-SEM). The morphology of tungsten trioxide $\left(\mathrm{WO}_{3}\right)$ was examined via FE-SEM. Figure 2 shows the SEM images for $\mathrm{WO}_{3}$ with the nanostructures clearly visible. The SEM images confirmed that the $\mathrm{WO}_{3}$ was nearly spherical in shape with an average grain size of approximately $20-30 \mathrm{~nm}$.

Figure 2 shows various types of tungsten trioxide nanostructures obtained by reaction of tungsten salt $\left(\mathrm{NH}_{4}\right)_{10} \mathrm{~W}_{12} \mathrm{O}_{41} \cdot 5 \mathrm{H}_{2} \mathrm{O}$ with aqueous ammonia at $80^{\circ} \mathrm{C}$ for 1 hour. Figure 2(a) shows the morphology of nanoparticles. The nanoparticles are entirely spherical in shape and have diameters varying between 23 and $25 \mathrm{~nm}$, with an average diameter of $24 \mathrm{~nm}$ as can be seen from figure. Figure 2(b) shows nanoparticles prepared at the resolution of $50.00 \mathrm{KX}$. Figure 2(c) shows nanoparticles prepared at the resolution of $25.00 \mathrm{KX}$ and Figure 2(d) shows nanoparticles prepared at the resolution of $10.00 \mathrm{KX}$. The nanoparticles of tungsten trioxide are having average dimension of $24 \mathrm{~nm}$ diameter.
These nanoparticles are less than those reported in the references $[42,43]$ and are also similar to those reported in references [44-47]. The effect of reaction time plays a marvelous role in the morphology of nanoparticles. The influence of reaction conditions on physical properties of synthesized nanoparticles as well as mechanism is yet to be investigated.

3.1.3. Structural Investigation of Tungsten Oxide Nanoparticles by XRD. The particle size was calculated using the Scherrer equation based on the XRD data as

$$
D=\frac{K \lambda}{\beta \cos \theta},
$$

where $D$ : particle size, $K$ : a dimensionless shape factor, with a value close to unity, $\lambda$ : the X-ray wavelength, $\beta$ : the line broadening at half the maximum intensity (FWHM), $\theta$ : the Bragg angle, $K=0.89$ for the spherical shape, $\lambda=0.97 \mathrm{~nm}$, $\beta$ : FWHM $(30)=0.234$, and $\theta=30$. So $D=23.97 \mathrm{~nm}$ particle size, where the ISCD/JCPDS card number for the synthesized oxide particles is 00-041-0371.

The XRD pattern for the tungsten trioxide nanoparticles is shown in Figure 3(a) and indicates a single-phase with a monoclinic structure. The peak intensities and positions agree well with the library data clarified in Figure 3(b).

\section{Conclusions}

This study used a new approach to synthesize malonic acid ester via the direct ozonolysis of palm olein, where the fine bubbles of ozone played an active role to cleave the double bonds. This method was used for the first time with a tungsten trioxide catalyst for the esterification of malonic acid and had the advantages of synthetic simplicity, an excellent $10 \%$ yield, short $2 \mathrm{~h}$ reaction time, and recyclability. Malonic acid ester was characterized using mass spectroscopy. The prepared nanoparticles have a spherical shape and diameter of $24 \mathrm{~nm}$ have been investigated by the FESEM \& XRD, respectively.

\section{Conflict of Interests}

The authors declare no conflict of interests. 


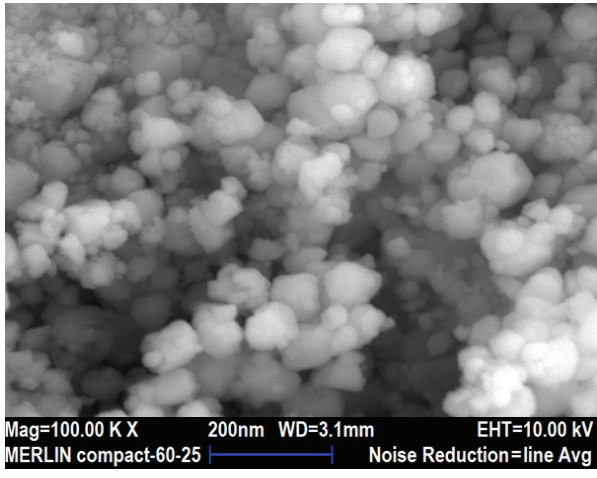

(a)

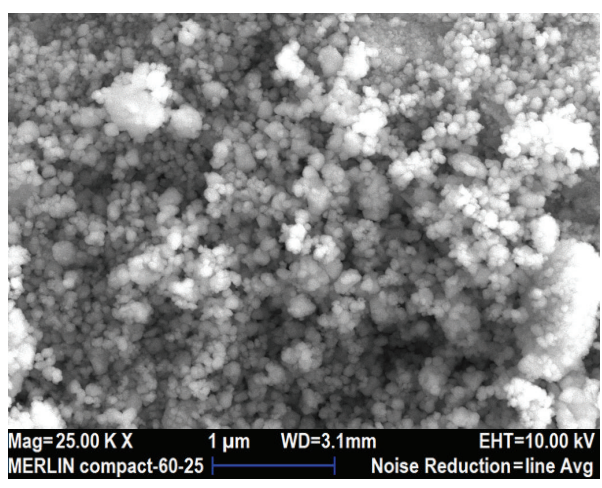

(c)

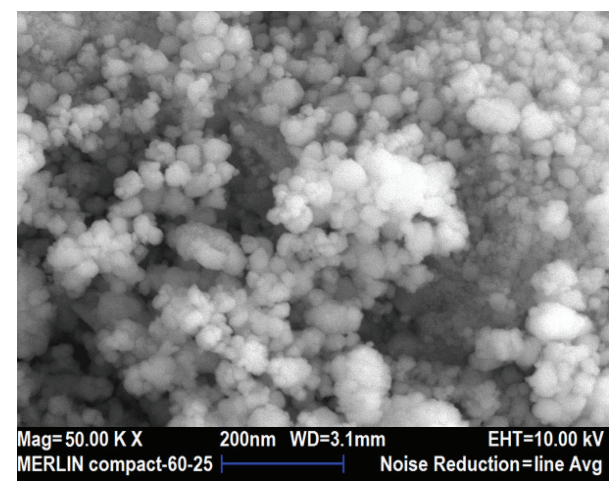

(b)

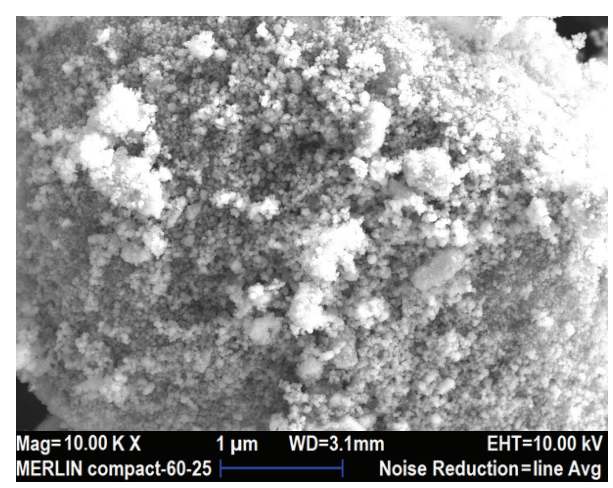

(d)

Figure 2: The SEM images (a) $100.00 \mathrm{KX}$, (b) $50.00 \mathrm{KX}$, (c) $25.00 \mathrm{KX}$, and (d) $10.00 \mathrm{KX}$ of $\mathrm{WO}_{3}$, Nanoparticals.

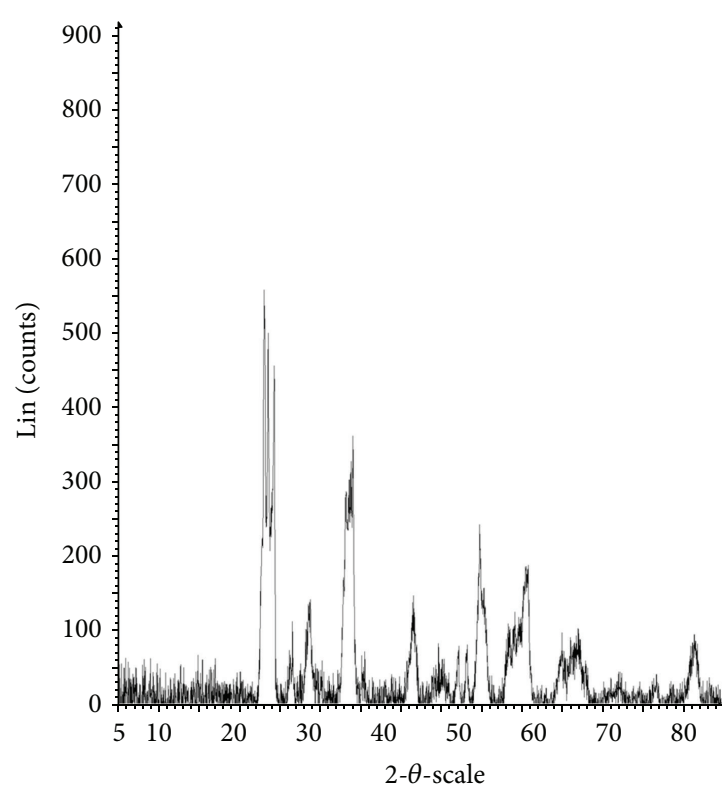

(a) $\mathrm{WO}_{3}$

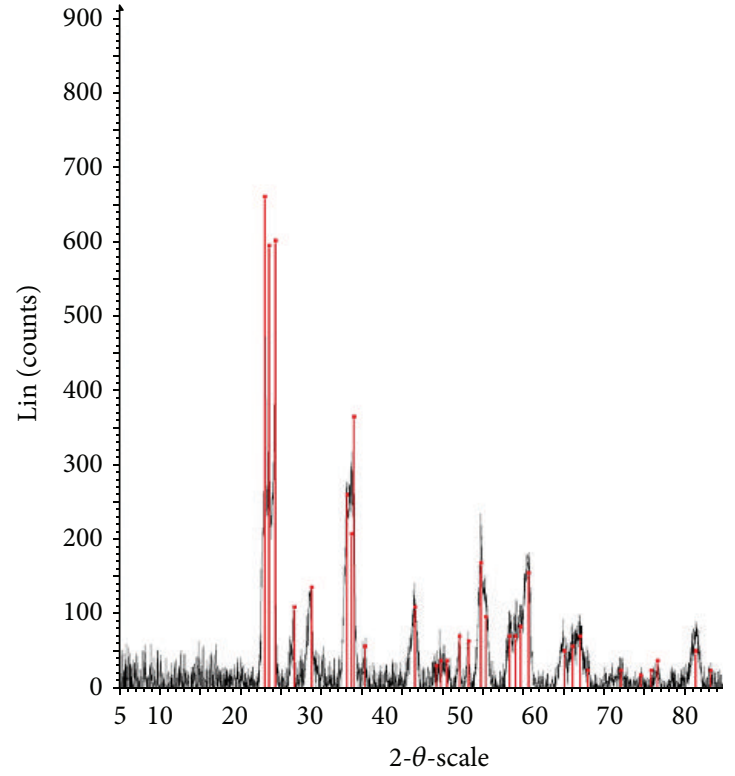

(b) $\mathrm{WO}_{3}$, Library

FIgURE 3: XRD for tungsten trioxide. 


\section{Acknowledgment}

The authors gratefully acknowledge the Universiti Kebangsaan Malaysia under the UKM-KK-02-FRGS0196-2010.

\section{References}

[1] M. Nadagouda, T. F. Speth, C. Impellitteri, and Y. Zhao, "Nanomaterials synthesis, applications, and toxicity," Journal of Nanotechnology, vol. 2011, Article ID 218562, 2 pages, 2011.

[2] R. Naik, C. Prashantha, H. Nagabhushana, S. Nagabhushana, B. M. Nagaswarupa, and H. P. Premkumar, "Low temperature synthesis and photoluminescence properties of red emitting $\mathrm{Mg}_{2} \mathrm{SiO}_{4}: \mathrm{Eu}^{3+}$ nanophosphor for near UV light emitting diodes," Sensors and Actuators B, vol. 195, pp. 140-149, 2014.

[3] Y. K. Mishra, S. Kaps, A. Schuchardt et al., "Versatile fabrication of complex shaped metal oxide nano-microstructures and their interconnected networks for multifunctional applications," KONA Powder and Particle Journal, vol. 31, pp. 92-110, 2014.

[4] V. Kumar, H. C. Swart, M. Gohain, S. Som, B. C. B. Bezuindenhoudt, and O. M. Ntwaeaborwa, "Influence of ultrasonication times on the tunable colour emission of $\mathrm{ZnO}$ nanophosphors for lighting applications," Ultrasonics Sonochemistry, vol. 21, pp. 1549-1556, 2014.

[5] V. Kumar, S. Som, M. M. Duvenhage, O. M. Ntwaeaborwa, and H. C. Swar, "Effect of Eu doping on the photoluminescence properties of $\mathrm{ZnO}$ nan ophosphors for red emission applications," Applied Surface Science, vol. 308, pp. 419-430, 2014.

[6] V. Kumar, S. Som, O. M. Ntwaeaborwa, E. Coetsee, and H. C. Swart, "Tunable and white emission from $\mathrm{ZnO}: \mathrm{Tb}^{3+}$ nanophosphors for solid state lighting applications," Chemical Engineering Journal, vol. 255, pp. 541-552, 2014.

[7] V. Kumar, S. Som, J. H. Neethling, M. Lee, O. Ntwaeaborwa, and H. C. Swart, "The role of surface and deep-level defects on the emission of tin oxide quantum dots," Nanotechnology, vol. 25, no. 13, Article ID 135701, 2014.

[8] C. G. Granqvist, "Electrochromic tungsten oxide films: review of progress 1993-1998," Solar Energy Materials \& Solar Cells, vol. 60, no. 3, pp. 201-262, 2000.

[9] M. Sun, N. Xu, Y. W. Cao, J. N. Yao, and E. G. Wang, "Nanocrystalline tungsten oxide thin film: preparation, microstructure, and photochromic behavior," Journal of Materials Research, vol. 15, no. 4, pp. 927-933, 2000.

[10] G. R. Bamwenda and H. Arakawa, "Visible light induced photocatalytic activity of tungsten trioxide powders," Applied Catalysis A, vol. 210, no. 1-2, pp. 181-191, 2001.

[11] M. Akiyama, J. Tamaki, N. Miura, and N. Yamazoe, “Tungsten oxide-based semiconductor sensor highly sensitive to NO and $\mathrm{NO}_{2}$," Chemistry Letters, vol. 16, pp. 11-14, 1991.

[12] A. A. Tomchenko, V. V. Khatko, and I. L. Emelianov, "WO3 thick-film gas sensors," Sensors and Actuators B, vol. 46, no. 1, pp. 8-14, 1998.

[13] D. S. Lee, S. D. Han, J. S. Hun, and D. D. Lee, "Nitrogen oxidessensing characteristics of $\mathrm{WO}_{3}$-based nanocrystalline thick film gas sensor," Sensors and Actuators B: Chemical, vol. 60, no. 1, pp. 57-63, 1999.

[14] A. Kleiman, S. Hu, A. Forman, G. Stucky, and E. McFarland, "Electrodeposition of $\alpha-\mathrm{Fe}_{2} \mathrm{O}_{3}$ doped with $\mathrm{Mo}$ or $\mathrm{Cr}$ as photo anodes for photo-catalytic water splitting," The Journal of Physical Chemistry C, vol. 112, pp. 15900-15907, 2008.
[15] W. Y. Teoh, F. Denny, R. Amal, D. Friedmann, L. Mädler, and S. E. Pratsinis, "Photocatalytic mineralisation of organic compounds: a comparison of flame-made $\mathrm{TiO}_{2}$ catalysts," Topics in Catalysis, vol. 44, no. 4, pp. 489-497, 2007.

[16] I. Cesar, A. Kay, J. A. G. Martinez, and M. Grätzel, “Translucent thin film $\mathrm{Fe}_{2} \mathrm{O}_{3}$ photoanodes for efficient water splitting by sunlight: nanostructure-directing effect of Si-doping," Journal of the American Chemical Society, vol. 128, no. 14, pp. 4582-4583, 2006.

[17] R. Abe, H. Takami, N. Murakami, and B. Ohtani, "Pristine simple oxides as visible light driven photocatalysts: highly efficient decomposition of organic compounds over platinumloaded tungsten oxide," Journal of the American Chemical Society, vol. 130, no. 25, pp. 7780-7781, 2008.

[18] H. Tada, T. Mitsui, T. Kiyonaga, T. Akita, and K. Tanaka, "Allsolid-state $\mathrm{Z}$-scheme inCdS-Au- $\mathrm{TiO}_{2}$ three-component nanojunction system," Nature Materials, vol. 5, pp. 782-786, 2006.

[19] T. Inoue, K. Ohtsuka, Y. Yoshida, Y. Matsuura, and Y. Kajiyama, "Metal oxide semiconductor $\mathrm{NO}_{2}$ sensor," Sensors and Actuators $B$, vol. 25, no. 1-3, pp. 388-391, 1995.

[20] J. Shieh, H. M. Feng, M. H. Hon, and H. Y. Juang, " $\mathrm{WO}_{3}$ and W-Ti-O thin-film gas sensors prepared by sol-gel dip-coating," Sensors and Actuators B: Chemical, vol. 86, no. 1, pp. 75-80, 2002.

[21] Y. Choi, G. Sakai, K. Shimanoe, N. Miura, and N. Yamazoe, "Preparation of aqueous sols of tungsten oxide dihydrate from sodium tungstate by an ion-exchange method," Sensors and Actuators B, vol. 87, no. 1, pp. 63-72, 2002.

[22] G. Antonio, T. Enrique, G. Amelia, C. Santiago, and M. Beatriz, "A new type of anomalous ozonolysis in strained allylic bicycloalkan-1-ols," Tetrahedron Letters, vol. 46, no. 31, pp. 51575159, 2005.

[23] C. Bessiere, M. Marcle, J. M. Morcrettel, and J. Tarascon, "Flexible electrochromic reflectance device based on tungsten oxide for infrared emissivity control," Journal of Applied Physics, vol. 91, pp. 1589-1594, 2003.

[24] S. Tieng, A. Kanaev, and K. Chhor, "New homogeneously doped $\mathrm{Fe}(\mathrm{III})-\mathrm{TiO}_{2}$ photocatalyst for gaseous pollutant degradation," Applied Catalysis A, vol. 399, no. 1-2, pp. 191-197, 2011.

[25] N. Yamazoe and K. Shimanoe, "Receptor function and response of semiconductor gas sensor," Journal of Sensors, vol. 2009, Article ID 875704, 21 pages, 2009.

[26] L. A. Rocha, E. F. Molina, K. J. Ciuffi, P. S. Calefi, and E. J. Nassar, "Eu (III) as a probe in titania thin films: the effect of temperature," Materials Chemistry and Physics, vol. 101, no. 1, pp. 238-241, 2007.

[27] Z. Lu, S. M. Kanan, and C. P. Tripp, "Synthesis of high surface area monoclinic $\mathrm{WO}_{3}$ particles using organic ligands and emulsion based methods," Journal of Materials Chemistry, vol. 12, no. 4, pp. 983-989, 2002.

[28] F. Xu and S. D. Tse, "Flame synthesis of aligned tungsten oxide nanowires," Applied Physics Letters, vol. 88, no. 24, Article ID 243115, 2006.

[29] Z. Liu, Y. Bando, and C. Tang, "Synthesis of tungsten oxide nanowires," Chemical Physics Letters, vol. 372, no. 1-2, pp. 179182, 2003.

[30] K. Liu, D. T. Foord, and L. Scipioni, "Easy growth of undoped and doped tungsten oxide nanowires with high purity and orientation," Nanotechnology, vol. 16, no. 1, pp. 10-14, 2005.

[31] F. C. Cheong, B. Varghese, Y. Zhu et al., " $\mathrm{WO}_{3-x}$ nanorods synthesized on a thermal hot plate," Journal of Physical Chemistry C, vol. 111, no. 46, pp. 17193-17199, 2007. 
[32] F. Liu, L. Li, F. Mo, J. Chen, S. Deng, and N. Xu, "A catalyzedgrowth route to directly form micropatterned $\mathrm{WO}_{2}$ and $\mathrm{WO}_{3}$ nanowire arrays with excellent field emission behaviors at low temperature," Crystal Growth and Design, vol. 10, no. 12, pp. 5193-5199, 2010.

[33] B. Q. Zeng, G. Y. Xiong, S. Chen, W. Z. Wang, D. Z. Wang, and Z. F. Ren, "Enhancement of field emission of aligned carbon nanotubes by thermal oxidation," Applied Physics Letters, vol. 89, no. 22, Article ID 223119, 2006.

[34] I. Matolinova, M. Gillet, E. Gillet, and V. Matolin, "A study of tungsten oxide nanowires self-organized on mica support," Nanotechnology, vol. 20, no. 44, Article ID 445604, 2009.

[35] W. H. Lai, J. Shieh, L. G. Teoh, I. M. Hung, C. S. Liao, and M. H. Hon, "Effect of copolymer and additive concentrations on the behavior," Nanotechnology, vol. 17, p. 110, 2006.

[36] S. Bailey, Ozonation in Organic Chemistry, vol. 1, Academic Press, New York, NY, USA, 1978.

[37] D. Johnson and G. Marston, "The gas-phase ozonolysis of unsaturated volatile organic compounds in the troposphere," Chemical Society Reviews, vol. 37, no. 4, pp. 699-716, 2008.

[38] C. Reichardt, Front Matter, in Solvents and Solvent Effects in Organic Chemistry, Wiley-VCH Verlag GmbH \& Co. KGaA, Weinheim, Germany, 3rd edition, 2004.

[39] H. I. S. Nogueira, A. M. V. Cavaleiro, J. Rocha, T. Trindade, and J. D. P. de Jesus, "Synthesis and characterization of tungsten trioxide powders prepared from tungstic acids," Materials Research Bulletin, vol. 39, no. 4-5, pp. 683-693, 2004.

[40] S. Supothina, P. Seeharaj, S. Yoriya, and M. Sriyudthsak, "Synthesis of tungsten oxide nanoparticles by acid precipitation method," Ceramics International, vol. 33, no. 6, pp. 931-936, 2007.

[41] X. Chang, S. Sun, and J. Han, "A simple route to large-scale production of tungsten trioxide nanoparticles," Materials Letters, vol. 65, no. 3, pp. 552-554, 2011.

[42] M. Iwasaki, M. Hara, H. Kawada, H. Tada, and S. Ito, "Cobalt ion-doped $\mathrm{TiO}_{2}$ photocatalyst response to visible light," Journal of Colloid and Interface Science, vol. 224, no. 1, pp. 202-204, 2000.

[43] M. A. Shah and N. Muzyyan, "A novel approach for the synthesis of tungsten trioxide nanostructures," Journal of King Abdulaziz University: Science, vol. 21, pp. 109-115, 2009.

[44] M. Breedon, P. Spizzirri, M. Taylor et al., "Synthesis of nanostructured tungsten oxide thin films: a simple, controllable, inexpensive, aqueous sol-gel method," Crystal Growth \& Design, vol. 10, no. 1, pp. 430-439, 2010.

[45] E. Widenkvist, R. A. Quinlan, B. C. Holloway, H. Grennberg, and U. Jansson, "Synthesis of nanostructured tungsten oxide thin films," Crystal Growth and Design, vol. 8, no. 10, pp. 37503753, 2008.

[46] D. Lu, B. Liang, A. Ogino, and M. Nagatsu, "Study of the synthesis of tungsten trioxide nanostructured arrays by tungsten hot filament chemical vapor deposition method and their field emission properties," Journal of Vacuum Science \& Technology $B$, vol. 28, p. C2A98, 2010.

[47] S. Jeona and K. Yong, "Morphology-controlled synthesis of highly adsorptive tungsten oxide nanostructures and their application to water treatment," Journal of Materials Chemistry, vol. 20, pp. 10146-10151, 2010. 

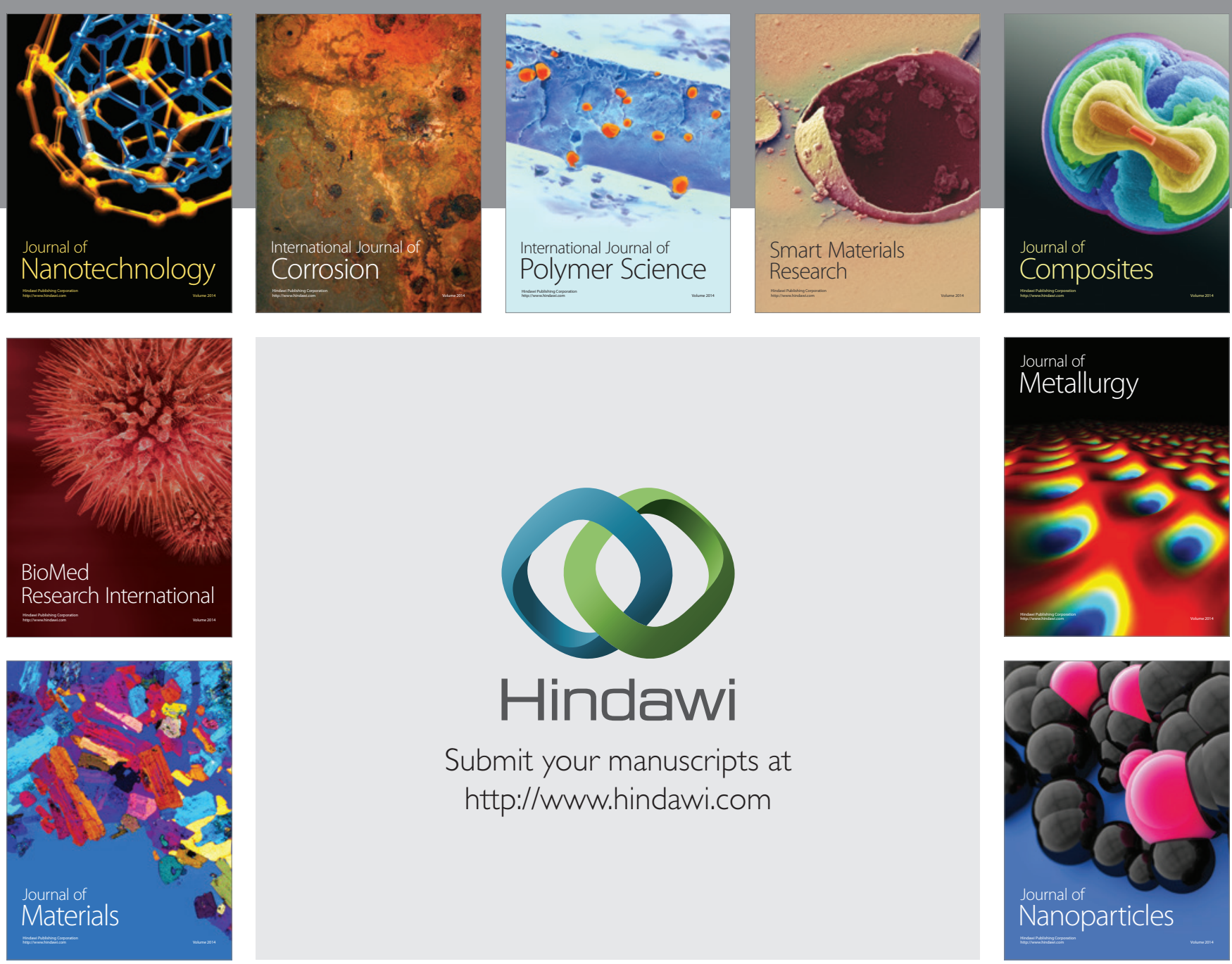

Submit your manuscripts at http://www.hindawi.com
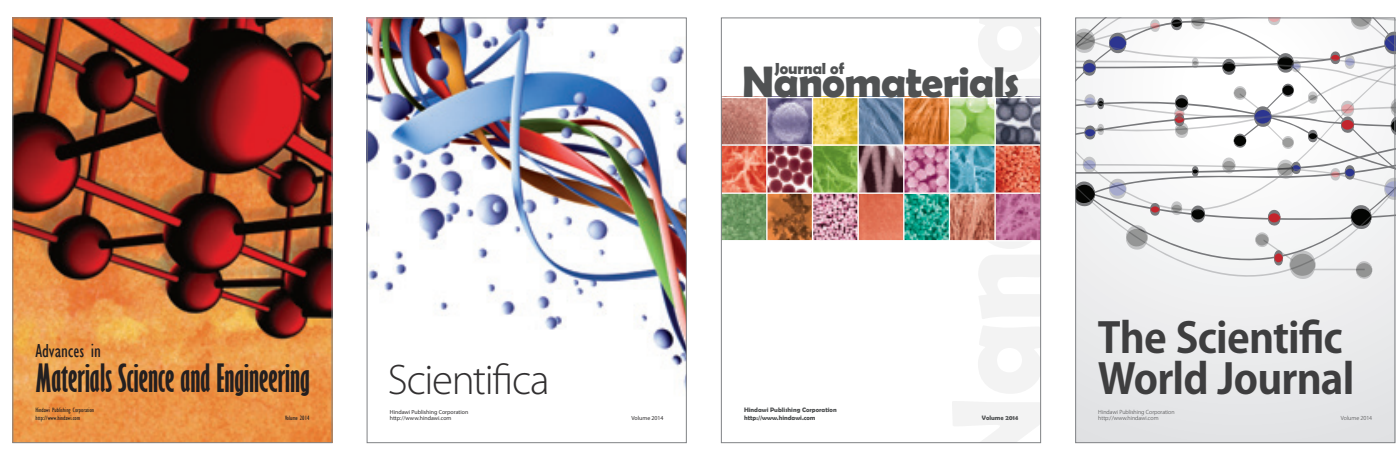

\section{The Scientific World Journal}
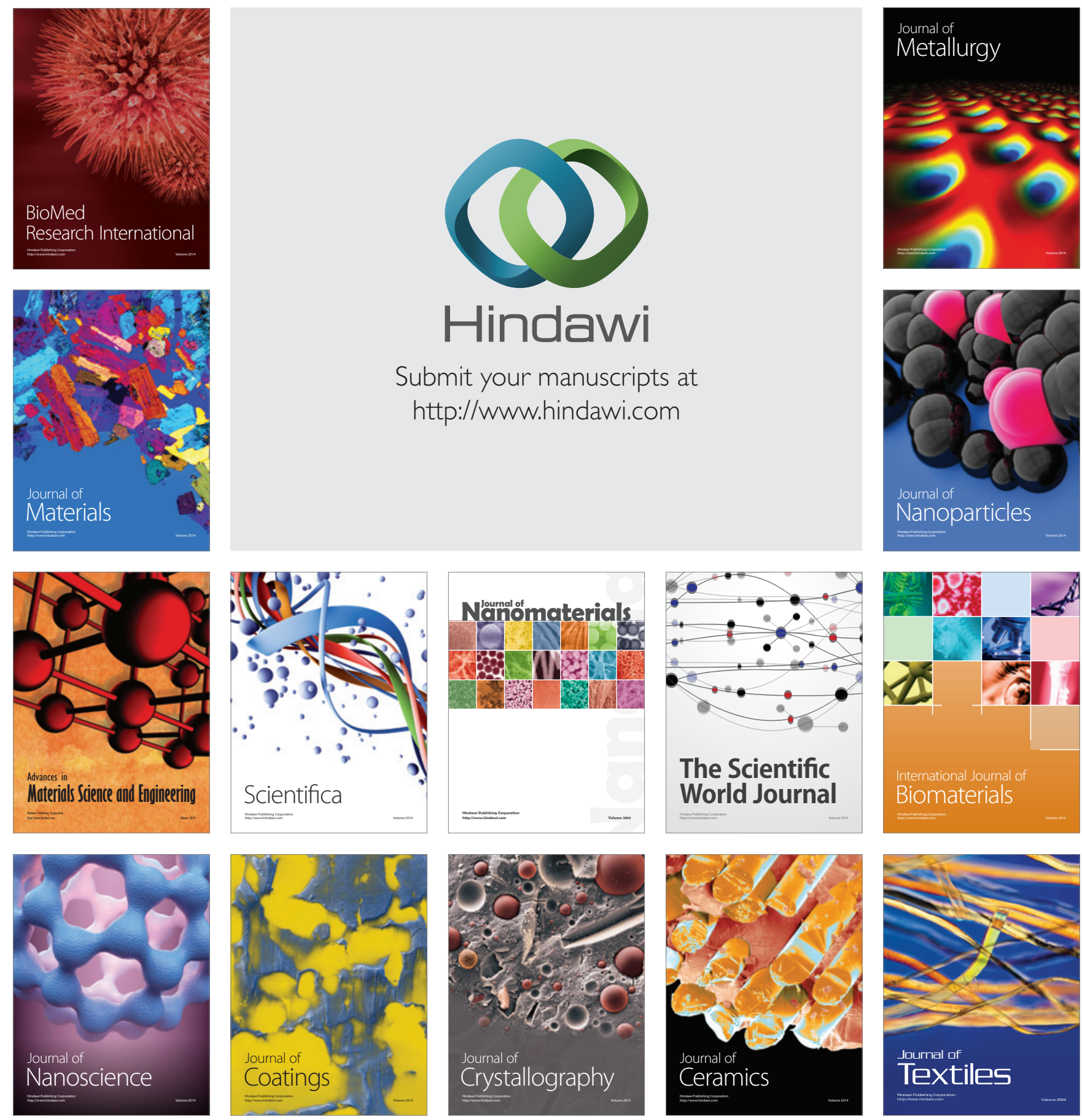